http://jurnaltarbiyah.uinsu.ac.id/index.php/raudhah

e-mail: jurnalraudhah@uinsu.ac.id

p-ISSN: 2338-2163

e-ISSN: $2716-2435$

\title{
Meningkatkan Kemampuan Menulis Dasar Anak Usia Dini Melalui Metode Demonstrasi TK Islam Nasrullah
}

\author{
${ }^{1}$ Ade Tursina, M.Pd \\ IAIN Langsa \\ Adetursina@iainlangsa.ac.id \\ https://orcid.org/0000-0002-4839-4403
}

\begin{tabular}{llll}
\hline Article received & $: 1$ Maret 2021 & Review process & $: 6$ Maret 2021 \\
Article accepted & $: 8$ Maret 2021 & Article published & $: 10$ Maret 2021
\end{tabular}

\begin{abstract}
Abstrak
Kemampuan menulis dasar anak belum berkembang secara optimal, kurangnya koordinasi otot-otot kecil anak dalam pembelajaran. Penelitian ini bertujuan untuk meningkatkan kemampuan menulis dasar melalui metode demonstrasi di kelas BI TK Islam Nasrullah. penelitian ini merupakan penelitian tindakan kelas kolaboratif dengan guru yang dilaksanakan dalam 2 siklus. Subjek penelitian ini adalah anak-anak kelas BI TK Islam Nasrullah yang berjumlah 25 anak. Teknik pengumpulan data yang digunakan dalam penelitian ini adalah observasi, wawancara dan dokumentasi. Instrumen pengumpulan data menggunakan lembar observasi. Analisisi data yang digunakan adalah deskriptif kualitatif dan kuantitatif. Peningkatan kemampuan menulis dasar dikatakan berhasil apabila persentase kemampuan mororik kasar anak mencapai 76-100 \% dengan kriterian Berkembang Sangat Baik (BSB). Hasil penelitian kemampuan menulis dasar Pra Tindakan dengan nilai rata-rata persentase sebesar $0 \%$. Hasil penelitian kemampuan menulis dasar melalui metode bermain peran pada siklus I dengan nilai rata-rata persentase sebesar 53,33\%. Setelah dilakukan tindakan pada siklus I telah berhasil meningkatkan kemampuan menulis dasar anak tetapi belum mencapai indikator keberhasilan sehingga diperlukan siklus selanjutnya. Hasil siklus II pencapaian kriteria Berkembang Sangat Baik (BSB) dengan nilai rata-rata sebesar $80 \%$. Berdasarkan hasil peningkatan ini diperoleh dari upaya peningkatan kemampuan menulis dasar anak melalui metode demonstrasi dalam kegiatan menulis.
\end{abstract}

Kata kunci: Menulis Dasar Anak; Metode Demonstrasi; Perkembangan Bahasa

\begin{abstract}
Children's basic writing skills have not developed optimally, the lack of coordination of the small muscles of children in learning. This study aims to improve basic writing skills through demonstration methods in the Nasrullah Islamic Kindergarten class BI. This research is a collaborative classroom action research with teachers conducted in 2 cycles. The subjects of this study were 25 children of the Nasrullah Islamic Kindergarten class BI. Data collection techniques used in this study were observation, interviews and documentation. The data collection instrument used an observation sheet. The data analysis used was descriptive qualitative and quantitative. Improving basic writing skills is said to be successful if the percentage of children's gross moral ability reaches 76-100\% with the Very Good Development (BSB) criteria. The results of the research on pre-action basic writing skills with an average percentage value of $0 \%$. The results of the research on basic writing skills through the role playing method in the first cycle with an average percentage value of 53.33\%. After the action in the first cycle has succeeded in improving the child's basic writing skills but has not reached the indicators of success so that the next cycle is needed. The results of the second cycle of achieving the criteria for Very Good Development (BSB) with an average value of $80 \%$. Based on the results of this increase obtained from efforts to improve children's basic writing skills through demonstration methods in writing activities.
\end{abstract}

Keywords: Children's Basic Writing; Demonstration Method; Language Development

Meningkatkan Kemampuan Menulis Dasar Anak Usia Dini Melalui Metode Demonstrasi di TK Islam Nasrullah Copyright (c) 2021 Tursina 
http://jurnaltarbiyah.uinsu.ac.id/index.php/raudhah

\section{A. PENDAHULUAN}

Anak usia dini merupakan masa golden age. Pada masa ini merupakan masa pertumbuhan cepat baik fisik maupun non fisik di luar kandungan. Golden age atau usia emas adalah usia 0-6 tahun yang merupakan masa dimana perkembangan fisik, motorik, intelektual, emosional, bahasa dan sosial berlangsung dengan sangat cepat yang hanya terjadi satu kali dalam perkembangan kehidupan manusia (Suyadi, 2013). Pendidikan bagi Anak Usia Dini sangatlah penting dikarenakan dengan adanya pendidikan di usia 0-6 tahun maka anak dapat mengembangkan seluruh aspek perkembangan yang ada pada diri anak sesuai dengan tahap perkembangaan (Nisa, 2017).

Pendidikan Anak Usia Dini (PAUD) merupakan salah satu bentuk penyelenggaraan pendidikan yang menitik beratkan pada peletakan dasar kearah pertumbuhan dan perkembangan fisik (koordinasi motorik halus dan kasar), kecerdasan (daya pikir, daya cipta, kecerdasan emosi, kecerdasan spiritual), Sosio-emosional (sikap dan perilaku serta agama) bahasa dan komunikasi, sesuai dengan keunikan dan tahap-tahap perkembangan yang dilalui oleh anak usia dini (Danar, 2009). Aspek-aspek perkembangan Anak Usia Dini meliputi aspek perkembangan kognitif, motorik, sosial, bahasa, moral, dan kesenian yang dapat di kembangkan dalam diri Anak Usia Dini. Salah satu dari aspek perkembangan anak usia dini yaitu aspek perkembangan motorik, khususnya motorik halus yang harus di kembangkan dalam diri anak. Motorik halus merupakan kemampuan anak prasekolah beraktivitas dengan menggunakan otot-otot halus (otot kecil) seperti menulis, menggambar (Samsudin, 2008).

Indikator yang terdapat dalam perkembangn motorik halus yaitu menggunting, melipat, menggambar, menulis, memegang dan lain sebagainya. Terdapat satu indikator yang peneliti dapatkan yaitu dalam permasalahan yang ada di TK tentang menulis. Menulis merupakan kegiatan yang produktif dan ekspretif. dalam kegiatan menulis penulis harus terampil dalam memanfatkan struktur bahasa dan kosa kata. Keterampilan menulis ini tidak datang secara otomatis, tetapi harus melalui latihan dan dan praktik yang banyak dan teratur (Susanto, 2014) Dengan kata lain Menulis bisa dilakukan oleh siap saja yang berkeinginan menulis akan tetapi membutuhkan keterampilan agar dapat menulis sesuai 
http://jurnaltarbiyah.uinsu.ac.id/index.php/raudhah

e-mail: jurnalraudhah@uinsu.ac.id

p-ISSN: 2338-2163

e-ISSN: $2716-2435$

yang di ingikan dan mengikuti praktik yang berulang-ulang agar dapat menulis dengan sempurna atau teratur.

Berdasarkan observasi awal di TK Islam Nasrullah di kelas B1, terdapat 25 siswa, 15 di antaranya siswa belum mampu menggunakan alat tulis dengan benar. Peneliti melihat pada waktu kegiatan menulis, kebanyakan anak dalam memegang alat tulis masih sulit dilakukan dilakukan oleh anak, begitu juga dalam kegiatan menulis, anak-anak menganggap bahwa sebuah coretan yang dibuatnya itu adalah sebuah tulisan atau bentuk lainnya, begitu juga dengan guru yang membenarkan bahwa coretan anak-anak terdsebut adalah huruf atau bentuk lainnya. akan tetapi itu bukan sebuah tulisan ataupun bentuk huruf melainkan sebuah coretan saja.

Anak tidak dapat menulis di sebabkan karena guru terlalu menekankan anak dalam melakukan sesuatu kegiatan tidak melihat dari sisi anak mampu tidaknya melakukannya, begitu juga dengan kelenturan tangan anak yang masih harus dikembangkan agar motorik halus dapat berkembang dengan baik, dan belum terbiasanya anak dalam menggunakan alat tulis. Peneliti melihat ketika proses guru memberikan stimulasi kepada anak, metode yang digunakan pada saat itu adalah metode demonstrasi. Namu peneliti melihat kurangnya antusias anak. Setelah diamati ternyata penyebabnya adalah Guru di TK Islam Nasrullah ini dalam menggunakan metode demonstrasi belum sesuai dengan langkahlangkah seharusnya, guru terlihat tidak memberikan contoh terlenbih dahulu serta tidak menjelaskan dengan mendalam tentang kegiatan yang akan dilakukan oleh anak dan membiarkan anak melakukan gegiatan dengan sendirinya tanpa ada arahan guru, sehingga membuat anak binggung.

Metode demonstrasi yang akan dilakukan oleh peneliti di TK Islam Nasrullah adalah menjelaskan kepada anak tentang materi yang akan di berikan atau yang akan di pelajari anak pada hari itu. Mempersiapkan media sesuai dengan tema dan menjelaskannya dengan terarah, anak juga dapat menyimak atau melakukan kegiatan menulis dengan terarah dan teratur. Dan mengarahkan anak dalam melakukan kegiatan baik itu dalam kegiatan menulis dan lainnya. Metode demonstrasi adalah metode penyajian pelajaran dengan memperagakan dan mempertunjukkan kepada siswa tentng suatu proses, situasi atau benda tertentu, baik sebenarnya atau hanya sekedar tiruan. Sebagai metode penyajian, 
http://jurnaltarbiyah.uinsu.ac.id/index.php/raudhah

e-mail: jurnalraudhah@uinsu.ac.id

p-ISSN: 2338-2163

e-ISSN: $2716-2435$

demonstrasi tidak terlepas dari penjelasan secara lisan oleh guru. Walaupun dalam proses demonstrasi peran siswa hanya memerhatikan, akan tetapi demonstrasi dapat menyajikan bahan pelajaran lebih konkret (Sanjaya, 2008). Peneliti menggunakan metode demonstrasi dikarenakan metode ini memudahkan anak dalam melakukan kegiatan menulis. Metode demonstrasi juga berbeda dengan metode yang lain, metode ini dapat memudahkan peserta didik dalam melakukan kegiatan belajar agar dapat menjadi lebih baik dan berkembang sesuai dengan tahap-tahap perkembangan anak.

Berdasarkan penemuan tersebut penulis tertarik mengkaji permasalahan ini kedalam sebuah penelitian tindakan kelas dengan judul "Upaya Meningkatkan Kemampuan Menulis Dasar melalui metode demonstrasi pada anak usia 5-6 tahun di TK Islam Nasrullah”. Tujuan Penelitian ini adalah untuk mengetahui aktivitas guru dalam meningkatkan kemampuan menulis dasar melalui metode demonstrasi pada anak usia 5-6 tahun di TK Islam Nasrullah.

\section{B. METODE PENELITIAN}

Penelitian ini menggunakan pendekatan kualitatif dan kuantitatif (mix method) karena peneliti ingin memperoleh data yang mendalam secara alami tentang penerapan metode demonstrasi dalam upaya peningkatan motorik halus anak, pada kegiatan menggunakan alat tulis dengan benar di TK Islam Nasrullah. Sedangkan penelitian ini menggunakan jenis penelitian tindakan kelas (PTK), dengan menggunakan model Kemmis dan MC Taggart yang menggunakan system spiral dimana setiap siklus terdiri dari tiga tahapan menurut (Maisarah, 2020) yaitu: (1) perencanaa, (2) pelaksaanaan dan pengamatan, dan (3) refleksi.

Penelitian ini dilaksanakan di Tk Islam Nasrullah Desa Tanjung Karang, kecamatan Karang Baru Kabupaten Aceh Tamiang. Subjek penelitian ini adalah Anak pada kelas B1 dengan jumlah anak sebanyak 25 orang yang terdiri dari 10 anak laki-laki dan 15 anak perempuan. Teknik pengumpulan data dilakukan dengan cara observasi, wawancara dan dokumentasi. Peneliti mengobservasi aktivitas guru dan anak. Jenis observasi yang digunakan dalam penelitian ini adalah observasi terstruktur yang dilakukan langsung oleh 
http://jurnaltarbiyah.uinsu.ac.id/index.php/raudhah

e-mail: jurnalraudhah@uinsu.ac.id

p-ISSN: 2338-2163

e-ISSN: $2716-2435$

penelitian dan di bantu 2 orang teman sejawat untuk mengamati kemampuan menulis dasar anak usia dini sesuai yang ada pada indikator penilaian.

Teknik analisis yang digunakan dalam penelitian ini adalah dengan menggunakan teknik analisis kuantitatif dan deskriptif kualitatif. Analisis data kualitatif, yaitu data yang berbentuk uraian mengenai aktifitas guru dan anak selama proses pembelajaran, serta kondisi selama proses pembelajaran berlangsung. Analisis data kuantitatif, yaitu penyajian data dalam bentuk persentase sederhana yang peroleh dari hasil observasi sesuai dengan kriteria. Hasil analisis data tersebut selanjutnya diinterpretasikan menjadi 4 kategori: sangat baik, baik, cukup, kurang. Data observasi aktivitas guru dalam merencakan, melaksanakan kegiatan pembelajaran dan aktifitas anak selama kegiatan belajar mengajar berlangsung dianalisis dengan menggunakan penghitungan persentase diadaptasi dari (Aqib, 2009). Penghitungannya sebagai berikut :

$$
P=f N \times 100 \%
$$

Keterangan :

$\mathrm{P}=$ Persentase yang dicari

$\mathrm{F}=$ Frekuensi atau banyaknya deskriptor kemampuan guru/anak yang muncul

$\mathrm{N}=$ Jumlah aktivitas keseluruhan

\section{HASIL TEMUAN DAN PEMBAHASAN}

\section{Deksripsi Hasil Penelitian Pra Siklus}

Data pra siklus ini diperoleh melalui hasil observasi. Ini merupakan langkah awal yang dilakukan peneliti sebelum melakukan penelitian tindakan kelas. Hasil observasi awal menunjukkan bahwa kemampuan Menulis dasar anak sebelum dilakukan dengan maksimal tindakan melalui metode demonstrasi menunjukan bahwa kemampuan menulis dasar anak masih belum berkembang baik. Rendahnya kemampuan menulis dasar anak terlihat dari beberapa anak yang belum mampu mengkoordinasikan otot-otot kecil yang ada pada tangan anak dalam melakukan kegiatan menulis dan guru juga belum menggunakan media atau cara lain yang lebih efektif dalam kegiatan menulis dasar sehingga anak kurang antusias dan optimalnya perkembangan motorik halus. Secara rinci dapat dipaparkan bahwa kemampuan menulis dasar anak pada pra tindakan yaitu mulai 
http://jurnaltarbiyah.uinsu.ac.id/index.php/raudhah

e-mail: jurnalraudhah@uinsu.ac.id

p-ISSN: 2338-2163

e-ISSN: $2716-2435$

berkembang (MB) sebanyak 10 anak atau 40\%, akan belum berkembang (BB) yaitu sebanyak 15 anak $60 \%$.

Tabel 1. Hasil Pra Tindakan Kemampuan Menulis Dasar Anak

\begin{tabular}{|l|c|c|c|c|c|}
\hline No & Nama Anak & Ket & No & Nama Anak & Ket \\
\hline 1 & AK & BB & 14 & MH & MB \\
\hline 2 & AF & MB & 15 & MU & MB \\
\hline 3 & AA & MB & 16 & NK & BB \\
\hline 4 & AN & BB & 17 & HW & BB \\
\hline 5 & ALF & MB & 18 & HF & MB \\
\hline 6 & BS & BB & 19 & NM & MB \\
\hline 7 & DA & BB & 20 & NP & BB \\
\hline 8 & LZ & BB & 21 & PA & BB \\
\hline 9 & MA & BB & 22 & PH & BB \\
\hline 10 & MZ & MB & 23 & SA & MB \\
\hline 11 & MF & BB & 24 & TM & BB \\
\hline 12 & MM & BB & 25 & NAM & MB \\
\hline 13 & MS & BB & & &
\end{tabular}

Tabel 2. Persentase Perkembangan Menulis Dasar Pra Tindakan

\begin{tabular}{|c|l|c|c|}
\hline \multirow{2}{*}{ No } & \multirow{2}{*}{ Perkembangan Motorik Kasar } & \multicolumn{2}{|c|}{ Siklus I } \\
\cline { 3 - 4 } & & F & $\%$ \\
\hline 1 & Berkembang Sangat Baik (BSB) & - & - \\
\hline 2 & Berkembang Sesuai Harapan (BSH) & - & - \\
\hline 3 & Mulai Berkembang (MB) & 10 & 40 \\
\hline 4 & Belum Berkembang (BB) & 15 & 60 \\
\hline \multicolumn{2}{|c|}{ Jumlah } & 25 & 100 \\
\hline
\end{tabular}


http://jurnaltarbiyah.uinsu.ac.id/index.php/raudhah

e-mail: jurnalraudhah@uinsu.ac.id

p-ISSN: 2338-2163

e-ISSN: $2716-2435$

\section{Deksripsi Hasil Penelitian Siklus I}

\section{A. Deskripsi hasil penelitian}

Berdasarkan perhitungan pada siklus I (Tabel 3) dapat diketahui bahwa perkembangan menulis dasar anak kelas B1 di TK Islam Nasrullah sudah mulai mengalami perubahan kearah perkembangan yang lebih baik. Secara rinci dapat dipaparkan bahwa kemampuan menulis dasar anak yaitu sudah mulai berkembang (MB) sebanyak 8 anak atau $53.33 \%$, akan tetapi masih ada anak yang belum berkembang (BB) yaitu sebanyak 7 anak $46.66 \%$.

Tabel 3. Hasil Penelitian Menulis Dasar Pada Siklus I

\begin{tabular}{|c|c|c|c|c|c|}
\hline No & $\begin{array}{c}\text { Nama } \\
\text { Anak }\end{array}$ & Ket & No & Nama Anak & Ket \\
\hline 1 & AK & BB & 9 & MS & BB \\
\hline 2 & AN & MB & 10 & NK & BB \\
\hline 3 & NS & BB & 11 & HW & MB \\
\hline 4 & DA & MB & 12 & NP & BB \\
\hline 5 & LZ & BB & 13 & PA & MB \\
\hline 6 & MA & MB & 14 & PH & BB \\
\hline 7 & MF & MB & 15 & TM & MB \\
\hline 8 & MM & MB & &
\end{tabular}

Tabel 4. Persentase Perkembangan Menulis Dasar Siklus I

\begin{tabular}{|c|l|c|c|}
\hline \multirow{2}{*}{ No } & \multirow{2}{*}{ Perkembangan Motorik Kasar } & \multicolumn{2}{|c|}{ Siklus I } \\
\cline { 3 - 4 } & & F & $\%$ \\
\hline 1 & Berkembang Sangat Baik (BSB) & - & - \\
\hline 2 & Berkembang Sesuai Harapan (BSH) & - & - \\
\hline 3 & Mulai Berkembang (MB) & 8 & 53.33 \\
\hline 4 & Belum Berkembang (BB) & 7 & 46.66 \\
\hline \multicolumn{2}{r|}{ Jumlah } & 15 & 100 \\
\hline
\end{tabular}


http://jurnaltarbiyah.uinsu.ac.id/index.php/raudhah

e-mail: jurnalraudhah@uinsu.ac.id

p-ISSN: 2338-2163

e-ISSN: $2716-2435$

Tabel 5. Hasil Rekapitulasi Aktivitas Guru Siklus I

\begin{tabular}{|c|c|c|c|c|}
\hline \multirow{2}{*}{ Tindakan } & \multicolumn{2}{|c|}{ Pengamat } & Rata-Rata & Keterangan \\
\cline { 2 - 3 } & P1(\%) & P2(\%) & $(\%)$ & \\
\hline I & 46 & 42 & $44 \%$ & MB \\
\hline II & 47 & 45 & $46 \%$ & MB \\
\hline III & 62 & 62 & $62 \%$ & BSH \\
\hline IV & 76 & 77 & $76.5 \%$ & BSB \\
\hline
\end{tabular}

Berdasarkan hasil pengamatan pada Tabel diatas Menunjukkan Bahwa observasi guru tindakan Siklus I memiliki peningkatan yang cukup dalam Proses Mengajar. Sedangkan Dari hasil observasi yang diamati tentang keseluruhan kegiatan anak selama mengikuti kegiatan pembelajaran, diperoleh hasil penelitian kemampuan menulis dasar anak.

\section{Deksripsi Hasil Penelitian Siklus II}

Observasi yang dilakukan terhadap guru yaitu dengan melihat aktivitas guru dalam kegiatan mengajar yang sesuai dengan RPPH melalui kegiatan bercerita dan untuk melihat kesesuaian antara perencanaan dengan pelaksanaan. Adapun hasil observasi terhadap kegiatan guru dalam mengajar dapat dilihat dari tabel 6 dibawah ini:

Tabel 6.Hasil Rekapitulasi Aktivitas Guru Siklus II

\begin{tabular}{|c|c|c|c|c|}
\hline \multirow[t]{2}{*}{ Tindakan } & \multicolumn{2}{|c|}{ Pengamat } & \multirow{2}{*}{$\begin{array}{l}\text { Rata-Rata } \\
(\%)\end{array}$} & \multirow[t]{2}{*}{ Ket } \\
\hline & P1(\%) & P2(\%) & & \\
\hline I & 77 & 81 & $79 \%$ & BSB \\
\hline II & 86 & 84 & $85 \%$ & BSB \\
\hline III & 88 & 88 & $88 \%$ & BSB \\
\hline IV & 94 & 95 & $94.5 \%$ & BSB \\
\hline
\end{tabular}

Berdasarkan hasil pengamatan pada Tabel diatas Menunjukkan Bahwa observasi guru tindakan Siklus II memiliki peningkatan yang sangat baik dalam Proses Mengajar. Sedangkan Dari hasil observasi yang diamati tentang keseluruhan kegiatan anak selama 
http://jurnaltarbiyah.uinsu.ac.id/index.php/raudhah

e-mail: jurnalraudhah@uinsu.ac.id

p-ISSN: 2338-2163

e-ISSN: $2716-2435$

mengikuti kegiatan pembelajaran, diperoleh hasil penelitian kemampuan menulis dasar anak. Adapun hasil pengamatan tentang kemampuan menulis dasar anak seperti yang terlihat pada tabel sebagai berikut:

Tabel 7. Hasil Penelitian Menulis Dasar Pada Siklus II

\begin{tabular}{|l|l|l|l|l|l|}
\hline No & $\begin{array}{l}\text { Nama } \\
\text { Anak }\end{array}$ & Ket & No & $\begin{array}{l}\text { Nama } \\
\text { Anak }\end{array}$ & Ket \\
\hline 1 & AK & BSB & 9 & MS & BSH \\
\hline 2 & AN & BSB & 10 & NK & BSB \\
\hline 3 & NS & BSB & 11 & HW & BSB \\
\hline 4 & DA & BSB & 12 & NP & BSH \\
\hline 5 & LZ & BSB & 13 & PA & BSH \\
\hline 6 & MA & BSB & 14 & PH & BSB \\
\hline 7 & MF & BSB & 15 & TM & BSH \\
\hline 8 & MM & BSH & \multicolumn{3}{|l}{} \\
\cline { 1 - 2 } & & & & &
\end{tabular}

Tabel 8.Persentase Perkembangan Menulis Dasar Siklus II

\begin{tabular}{|c|c|c|c|}
\hline \multirow{2}{*}{ No } & Perkembangan Motorik Kasar & \multicolumn{2}{|c|}{ Siklus II } \\
\cline { 3 - 4 } & & F & $\%$ \\
\hline 1 & Berkembang Sangat Baik (BSB) & 12 & 80 \\
\hline 2 & Berkembang Sesuai Harapan (BSH) & 3 & 20 \\
\hline 3 & Mulai Berkembang (MB) & - & - \\
\hline 4 & Belum Berkembang (BB) & - & - \\
\hline & Jumlah & 15 & 100 \\
\hline
\end{tabular}

Berdasarkan hasil observasi tersebut, dapat diketahui bahwa kemampuan menulis dasar anak kelas BI di TK Islam Nasrullah sudah mencapai tingkat ketuntasan sebesar 80\%. Hasil ini menunjukan bahwa kemampuan menulis dasar anak melalui metode Demonstrasi sudah Berkembang Sangat Baik (BSB). Secara rinci dapat dipaparkan terdapat 3 atau 20\% anak dengan kemampuan menulis dasar sudah Berkembang Sesuai Harapan (BSH) dan 12 atau 80\% anak dengan kemampuan menulis dasar sudah 
http://jurnaltarbiyah.uinsu.ac.id/index.php/raudhah

e-mail: jurnalraudhah@uinsu.ac.id

p-ISSN: 2338-2163

e-ISSN: $2716-2435$

Berkembang Sangat Baik (BSB).Berdasarkan hasil pembelajaran yang dilaksanakan pada siklus II, disimpulkan bahwa keterampilan menulis dasar anak sudah berkembang sangat baik. Nilai perkembangan keterampilan motorik halus dalam kegiatan menulis dasar yang diperoleh telah memenuhi target hasil belajar anak secara keseluruhan yang sudah ditentukan sebelumnya yaitu kriteria keberhasilan tindakan penelitian sudah mencapai 80\%. Adapun secara rinci hasil pra penelitian, siklus I dan siklus II dapat dipaparkan sebagai berikut :

Tabel 9. Deskripsi Perkembangan Menulis Dasar Anak di TK Islam Nasrullah pada Pra Tindakan Penelitian, Siklus I, Siklus II

\begin{tabular}{|c|l|c|c|c|c|c|c|}
\hline \multirow{2}{*}{ No } & Perkembangan Motorik Kasar & \multicolumn{2}{|c|}{$\begin{array}{c}\text { Pra } \\
\text { Tindakan }\end{array}$} & \multicolumn{2}{l|}{ Siklus I } & \multicolumn{2}{l|}{ Siklus II } \\
\cline { 3 - 8 } & & F & $\%$ & F & $\%$ & F & $\%$ \\
\hline 1 & Berkembang Sangat Baik (BSB) & - & - & - & - & 12 & 80 \\
\hline 2 & Berkembang Sesuai Harapan (BSH) & - & - & - & - & 3 & 20 \\
\hline 3 & Mulai Berkembang (MB) & 10 & 40 & 8 & 53,33 & - & - \\
\hline 4 & Belum Berkembang (BB) & 15 & 60 & 7 & 46,66 & - & - \\
\hline \multicolumn{2}{|c|}{ Jumlah } & 25 & 100 & 15 & 100 & 25 & 100 \\
\hline
\end{tabular}

Berdasarkan paparan hasil penelitian di atas dapat disimpulkan bahwa penelitian sudah mencapai tingkat ketuntasan hasil belajar yang sudah ditentukan sebelumnya yaitu batas ketuntasan secara klasikal dari hasil belajar anak ialah 76-100\%. Jadi berdasarkan kriteria tersebut dapat dikatakan bahwa penelitian yang di lakukan di TK Islam Nasrullah pada kelas BI ini sudah dapat dikatakan berhasil, hal ini ditinjau dari hasil penelitian pada siklus II yaitu sudah mencapai $80 \%$. Untuk memudahkan dalam melihat hasil penelitin yang sudah dilakukan peneliti membuat bentuk diagram sebagai berikut: 


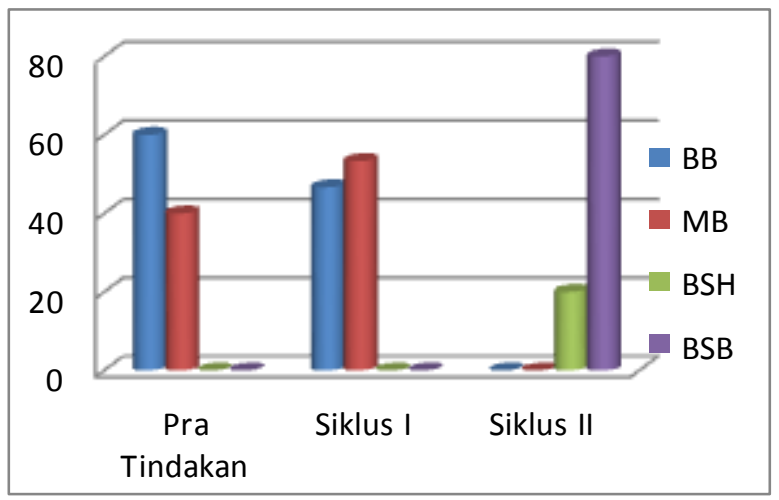

\section{Gambar 1. Kemampuan Menulis Dasar Anak Usia Dini Melalui Metode Demonstrasi di TK Islam Nasrullah}

\section{Pembahasan Hasil Penelitian}

Beberapa penelitian juga menunjukkan hasil yang sama yaitu adanya peningkatan kemampuan menulis permulaan melalui Beberapa penelitian juga menunjukkan hasil yang sama yaitu adanya peningkatan kemampuan menulis permulaan melalui permainan plastisin di taman kanak-kanak al-faruqiyah cipondoh tangeran, terbukti dapat meningkatkan menulis pemula pada anak dan dapat diterima (Kusumawati \& Sunaria, 2017). Penerapan metode pembelajaran yang tepat yaitu metode demostrasi dapat meningkatkan kemampuan menulis awal anak karena pembelajaran dengan menggunakan metode ini dapat merangsang kemampuan motorik halus anak dikarenakan pada saat menggunakan metode demonstrasi guru memberikan ilustrasi dalam menjelaskan informasi kepada anak secara langsung bagaimana sesuatu peristiwa terjadi, lebih menarik, dan merangsang perhatian serta lebih menantang anak, ketika menggunakan metode demonstrasi anak dapat melihat dan mempraktekkan secara langsung sehingga dalam proses pembelajaranmya amnak terlihat sangat antusias di bandingkan dari pada hanya mendengar penjelasan guru ( Hardiyati, 2014)

Metode Demontrasi juga memiliki banyak kelibihan dibandikan metode yamg lainnya, metode ini mempunyai manfaat bagi anak maupun guru dalam rangka pencapaian tujuan pembelajaran. Penerapan metode ini, mengharuskan guru untuk lebih kreatif. Guru harus terampil dan jelas dalam mendemonstrasikan sesuatu dihadapan anak, sehingga metode inisangat cocok digunakan untuk anak usia dini , agar anak memotivasi dan 
http://jurnaltarbiyah.uinsu.ac.id/index.php/raudhah

e-mail: jurnalraudhah@uinsu.ac.id

p-ISSN: 2338-2163

e-ISSN: $2716-2435$

antusias dalam proses pembelajaran. (Rosana, 2014). Dari beberapa penelitian terdahulu dapat di simpulkan sejalan dengan penelitian yang saya lakukan bahwa adanya Peningkatan kemampuan motorik halus dalam kegiatan menulis dasar melalui metode demonstrasi di kelas BI TK Islam Nasrullah dapat dilihat dari hasil penilaian tentang kemampuan motorik halus dengan rata-rata persentase pada pra tindakan sebesar $0 \%$, pada siklus I peningkatan kemampuan menulis dasar anak melalui metode demonstrasi menjadi 53,33 (5)\%, dan pada siklus II mengalami peningkatan mencapai $80 \%$. Dengan demikian dapat disimpulkan bahwa terdapat peningkatan kemampuan menulis dasar di kelas BI TK Islam Nasrullah. Melalui metode demonstrasi anak dapat mengeksplorasikan hal-hal yang ingin mereka lakukan tanpa ada paksaan dari orang lain. Melalui kegiatan menulis dasar anak dapat bebas mempraktekannya, dengan demikian kemampuan motorik halus dalam kegiatan menulis dasar anak dapat teroptimalkan dengan baik, anak dapat terbiasa dengan baik, sehingga kemampuan menulis dasarnya dapat teroptimalkan dengan sempurna.

\section{SIMPULAN DAN SARAN}

Berdasarkan hasil penelitian dapat dinyatakan bahwa adanya Peningkatan kemampuan motorik halus dalam kegiatan menulis dasar melalui metode demonstrasi di kelas BI TK Islam Nasrullah dapat dilihat dari hasil penilaian tentang kemampuan motorik halus dengan rata-rata persentase pada pra tindakan sebesar 0\%, pada siklus I peningkatan kemampuan menulis dasar anak melalui metode demonstrasi menjadi 53,33 (5)\%, dan pada siklus II mengalami peningkatan mencapai 80\%. Dengan demikian dapat disimpulkan bahwa terdapat peningkatan kemampuan menulis dasar di kelas BI TK Islam Nasrullah.

Berdasarkan hasil penelitian dan pembahasan pelaksanaan tindakan dan analisis penelitian terkait tentang upaya peningkatan kemampuan menulis dasar melalui metode demonstrasi, perlu adanya perbaikan dan saran yang membagun. Adapun saran-saran tersebut antara lain: (1) Bagi guru, diharapkan dapat menggunakan metode demonstrasi untuk peningkatan aspek-aspek kemampuan anak seperti pada kemampuan kognitif, bahasa, seni, sosial-emosional, agama, kreativitas anak, dan lain-lain. Guru hendaknya senantiasa meningkatkan kualitas pembelajaran yang dilaksanakan dengan metode demonstrasi atau media lain yang bervariasi dan cocok dalam pelaksanaan pembelajaran 
http://jurnaltarbiyah.uinsu.ac.id/index.php/raudhah

e-mail: jurnalraudhah@uinsu.ac.id

p-ISSN: 2338-2163

e-ISSN: $2716-2435$

keterampilan sehingga dapat menumbuhkan semangat peserta didik dalam mengikuti kegiatan pembelajaran; dan (2) Bagi Peneliti, kemampuan menulis dasar anak merupakan aspek yang sangat penting bagi perkembangan anak dimasa mendatang, oleh sebab itu peneliti selanjutnya diharapkan dapat membuat penelitian mengenai kemampuan motorik halus anak dalam kegiatan menulis dasar melalui berbagai metode, media, model yang lain yang lebih menarik bagi anak.

\section{DAFTAR PUSTAKA}

Aqib, Z. (2009). Penelitian Tindakan Kelas. Bandung: Yrama Widiya.

Danar, S. (2009). Pendidikan Anak Usia Dini. Indeks.

Ilmiah, N. P., \& Hardiyati, S. R. I. (2014). Upaya peningkatan kemampuan menulis awal melalui permainan finger painting pada anak kelompok a di tk pertiwi ii blimbing tahun ajaran 2013/2014.

Kusumawati, A., \& Sunaria. (2017). Peningkatan Kemampuan Menulis Permulaan Pada Anak Usia 5-6 Tahun Melalui Permainan Plastisin (Penelitian Tindakan Kelas di Taman Kanak-Kanak Al-Faruqiyah Cipondoh Tangerang). 7-13.

Maisarah. (2020). PTK dan Manfaatnya Bagi Guru. Bandung: Media Sains Indonesia.

Nisa, N. K. (2017). Strategi Pendidikan Anak Usia Dini. 1-3.

Rosana, E. (2014). BERBANTUAN MULTIMEDIA POWER POINT PADA SISWA KELAS IV SDN PURWOYOSO 06 SEMARANG oleh.

Samsudin. (2008). Pembelajaran Motorik Di Taman Kanak-Kanak. Prenada Media Group. Sanjaya, W. (2008). TitleStrategi Pembelajaran. Kencana.

Susanto, A. (2014). No TitleTeori Belajar Dan Pembelajaran. Kencana. 